\title{
Efeito da temperatura sobre a germinação e crescimento inicial de sementes de Capsicum frutescens (L.)
}

\section{Effect of temperature on germination and initial growth of seeds of Capsicum frutescens}

\author{
Sheila Bigolin Teixeira ${ }^{l}$; Kassia Luiza Teixeira Cocco ${ }^{l}$; Angelita Martins Celente ${ }^{l}$; Dominique dos Santos Delias ${ }^{l}$; Fernanda \\ Reolon $^{1 *}$; Dario Munt de Moraes ${ }^{1}$
}

\begin{abstract}
Resumo: A oscilação de temperatura, provocada pelas mudanças climáticas, vem afetando a agricultura em diversos pontos de áreas agricultáveis, com isso, há a necessidade da realização de estudos quanto à adaptabilidade das culturas a uma ampla faixa de temperatura. Desta forma, o objetivo do estudo foi verificar a eficiência da germinação e estabelecimento inicial de plântulas de pimenta malagueta submetidas a temperaturas sub e supra ótimas. O experimento foi conduzido em delineamento experimental inteiramente casualizado, em esquema fatorial constituído por uma espécie e três temperaturas $\left(15^{\circ} \mathrm{C}, 25^{\circ} \mathrm{C}\right.$ e 35 ${ }^{\circ} \mathrm{C}$ ). As sementes foram submetidas aos testes de germinação, sob fotoperíodo de 12 horas durante 14 dias, juntamente com primeira contagem de germinação, índice de velocidade de germinação, comprimento de plântulas, massa seca total, condutividade elétrica, atividade respiratória e curva de embebição sob as temperaturas de 15,25 e $35^{\circ} \mathrm{C}$. A temperatura de 25 ${ }^{\circ} \mathrm{C}$ apresentou superioridade aos demais tratamentos em todas as variáveis testadas. Nas temperaturas de 15 e $35{ }^{\circ} \mathrm{C}$, a germinação foi completamente inibida. Testes como os executados no presente estudo são eficientes para a determinação da viabilidade das sementes em diferentes faixas de temperatura.
\end{abstract}

Palavras-chave: Pimenta malagueta; Termoinibição; Vigor

\begin{abstract}
The temperature oscillation, provoked by the climatic changes, has been affecting the agriculture in several points of agricultural areas, with that, it is necessary to carry out studies on the adaptability of the crops to a wide range of temperature. Thus, the objective of the study was to verify the efficiency of the germination and initial establishment of chilli pepper seedlings submitted to sub and supra optimal temperatures. The experiment was conducted in a completely randomized experimental design, in a factorial scheme consisting of one species and three temperatures $\left(15^{\circ} \mathrm{C}, 25^{\circ} \mathrm{C}\right.$ and $\left.35^{\circ} \mathrm{C}\right)$. The seeds were submitted to germination tests, under a photoperiod of 12 hours for 14 days, together with first germination count, germination speed index, seedling length, total dry mass, electrical conductivity, respiratory activity and imbibition curve under the temperatures of 15,25 and $35^{\circ} \mathrm{C}$. The temperature of $25^{\circ} \mathrm{C}$ presented superiority to the other treatments in all variables tested. At temperatures of 15 and $35^{\circ} \mathrm{C}$, germination was completely inhibited. Tests such as those performed in the present study are efficient for the determination of seed viability in different temperature ranges.
\end{abstract}

Keywords: Chilli pepper; Thermoinhibition; Vigor

\footnotetext{
*Autor para correspondência

Recebido para publicação em 14/08/2017; aprovado em 23/12/2017

${ }^{1}$ Mestra Engenheira Agrônoma, Universidade Federal de Pelotas, Pelotas-RS, Fone (53)99604061, sheila_bigoli@ @otmail.com;

2Doutora Engenheira Agrônoma, Universidade Federal de Pelotas, kassiacocco@hotmail.com;

${ }^{3}$ Mestra Bióloga, Universidade Federal de Pelotas, angel-celente@ hotmail.com;

${ }^{4}$ Mestra Bióloga, Universidade Federal de Pelotas, domi_delias@ hotmail.com;

${ }^{5}$ Doutora Bióloga, Universidade Federal de Pelotas, fernandareolon@yahoo.com.br;

${ }^{6}$ Doutor Engenheiro Agrônomo, Universidade Federal de Pelotas, moraesdm@ufpel.edu.br
} 


\section{INTRODUÇÃO}

A espécie Capsicum frutescens (L.), conhecida popularmente como pimenta malagueta, pertence à família Solanacea e ao gênero Capsicum (do grego kapto, que significa morder, picar), apresenta um fruto alongado, ereto, com cerca de $2 \mathrm{~cm}$ de comprimento, $0,5 \mathrm{~cm}$ de largura e coloração vermelha forte (maduro) ou verdes (imaturo), em média. Sua pungência varia de média a alta e seu aroma é baixo. Estão distribuídas por toda a América Central e planícies da América do Sul e também em outras regiões tropicais e subtropicais (CATELAM, 2016).

No Brasil, as pimentas são cultivadas do Rio Grande do Sul até Roraima, sendo Minas Gerais, Goiás, São Paulo, Ceará e Rio Grande do Sul os principais produtores (PAULUS et al., 2015). A pimenta é geralmente conhecida por seu sabor picante e mais de 25 por cento da população do mundo a consome todos os dias. É considerada uma cultura importante, de grande relevância econômica, na qual o fruto é a parte mais explorada devido ao seu valor nutricional, além de servir como fonte de corantes e compostos antioxidantes (EREMRENA et al.,2016). Em sua maioria, as pimentas possuem sabor pungente característico devido à presença do alcaloide capsaicina na placenta e, em menor quantidade, nas sementes e no pericarpo do fruto (DOMENICO et al., 2012; CATELAM, 2016). A pungência é uma característica de qualidade para pimentas frescas e também para produtos processados, sendo o conteúdo de capsaicina um dos requisitos majoritários para determinar a qualidade comercial dos frutos de pimenta. A importância da capsaicina se deve a diversos fatores, mas principalmente ao fato de ser o princípio ativo que representa as propriedades farmacêuticas das pimentas e por ser a principal responsável pela sensação de ardor (PAULUS, 2015).

$\mathrm{O}$ aumento no consumo de pimenta resulta em um mercado recente e emergente, que busca aprimorar pesquisas visando a tecnificação da produção e obtenção de sementes com alta qualidade genética, física, fisiológica e sanitária, gerando maior uniformidade e vigor das plântulas e, consequentemente maior produtividade final (CAIXETA et al., 2014). A produção de sementes é uma atividade especializada e cuidados devem ser tomados em todas as fases de produção para assegurar a obtenção de lotes de sementes com alta qualidade. Umas das etapas importantes para obtenção de resultados positivos na produção de sementes e, consequentemente, a formação de frutos de qualidade, é encontrada na etapa de germinação, onde ocorre uma sequência ordenada de eventos metabólicos que resulta na formação da plântula. Esse processo depende de vários fatores ambientais, como temperatura, luz, disponibilidade de oxigênio e de água. Quando estes fatores são otimizados as sementes expressam o seu potencial máximo de germinação, característica importante para se obter um estabelecimento rápido e uniforme das plântulas em campo (DIAS et al., 2008).

A temperatura influencia tanto na porcentagem quanto na velocidade de germinação, interferindo na velocidade de absorção da água e nas reações bioquímicas (GORDIN, 2012). Vários estudos têm demonstrado que a luz e a temperatura interferem na germinação da semente de diferentes espécies (BERGO, 2010). Cada espécie apresenta temperatura mínima, máxima, e ótima para a germinação, e dentro desta, podem existir diferenças marcantes entre as cultivares quanto à germinação (NASCIMENTO, 2005; OLIVEIRA, 2014). Para o cultivo da pimenta verificou-se que as temperaturas máximas e mínimas estão dentro da faixa de $35{ }^{\circ} \mathrm{C}$ de temperatura máxima e $18{ }^{\circ} \mathrm{C}$ de temperatura mínima (PAULUS, 2015).

Para o uso de sementes na implantação das culturas, alguns fatores devem ser considerados, sendo que em algumas espécies de pimenteira podem apresentar sementes com dormência e baixas taxas de germinação (RICCI, 2013), o que varia entre os lotes e em função do vigor. Portanto, o uso de sementes de alta qualidade fisiológica e/ou tratamentos que possibilitem maior expressão de potencial destas são essenciais (BATISTA, 2015).

A investigação de faixas de temperaturas que permitem uma satisfatória germinação da cultura nos fornece informações importantes sobre adaptabilidade e indicações de épocas de semeadura em diferentes locais. Quanto maior a amplitude térmica aceitada, maior o período favorável ao estabelecimento da cultura e maior será a disponibilidade de produto fresco para o mercado consumidor.

Assim, objetivou-se avaliar o efeito de temperaturas sub e supra ótimas sobre a germinação e estabelecimento inicial de plântulas pimenta malagueta cv. Iracema biquinho.

\section{MATERIAL E MÉTODOS}

O trabalho foi realizado no Laboratório de Fisiologia de Sementes, pertencente ao Departamento de Botânica, da Universidade Federal de Pelotas. A análise foi conduzida utilizando-se sementes comerciais de pimenta malagueta, espécie Capsicum frutescens, cv Iracema biquinho.

A curva de embebição foi realizada em três repetições de 50 sementes cada, com quatro subamostras, totalizando 600 sementes. Foram feitas pesagens consecutivas, inicialmente em intervalos de trinta minutos $\left(0,300^{\circ}, 60^{\prime}, 90^{\prime}\right)$ e, posteriormente, em intervalos de 60 minutos, sendo a última pesagem realizada após 24 horas, totalizando 10 períodos de embebição, com auxílio de balança analítica de precisão, até ocorrerem pequenos aumentos e decréscimos de maneira sistemática no peso da biomassa (MORAES, 2012). Após cada pesagem, as sementes foram devolvidas imediatamente para os frascos com água destilada e, no fim da obtenção de todas as pesagens, foi calculada a porcentagem de água absorvida (em cada tempo), onde a porcentagem de embebição das sementes foi igual a razão do peso final menos o peso inicial multiplicado por 100 .

Para o teste de germinação, as sementes de pimenta foram semeadas sobre folhas de papel germitest umedecido com água destilada, em quantidade equivalente a 2,5 vezes o peso do papel seco, em caixas gerbox. Para tanto, foram utilizadas três repetições de quatro subamostras cada, contendo 50 sementes, totalizando 600 sementes. As caixas gerbox foram mantidas em germinador do tipo BOD, com temperatura constante de $15{ }^{\circ} \mathrm{C}, 25{ }^{\circ} \mathrm{C}$ e $35^{\circ} \mathrm{C}$, sob fotoperíodo de 12 horas ocorrendo a contagem ao décimo quarto dia após a semeadura. Os resultados foram expressos em porcentagem de plântulas normais, de acordo com as Regras para Análise de Sementes (BRASIL, 2009).

A primeira contagem de germinação (PCG) foi realizada juntamente com o teste de germinação, aos sete dias após a semeadura, conforme as Regras de Análise de Sementes 
(BRASIL, 2009), e os resultados expressos em porcentagem de plântulas normais. Simultaneamente ao teste de germinação, foi realizado o índice de velocidade de germinação (IVG), mediante a contagem diária do número de plântulas germinadas, identificadas a partir da protrusão da radícula até o momento em que o número de plântulas germinadas permanecesse estável. O cálculo do índice de velocidade de germinação foi efetuado de acordo com Maguire (1962), utilizando a seguinte fórmula: IVE $=$ G1/N1 $+\mathrm{G} 2 / \mathrm{N} 2+\ldots+\mathrm{En} / \mathrm{Nn}$, onde: G1, G2, Gn = número de sementes germinadas, computadas na primeira contagem, na segunda e última contagem. $\mathrm{N} 1, \mathrm{~N} 2, \mathrm{Nn}=$ número de dias de semeadura a primeira, segunda e última contagem.

Ao final do teste de germinação foi determinado o comprimento das plântulas, cuja medição foi realizada no décimo quarto dia após a semeadura (NAKAGAWA, 1999). Os comprimentos das plântulas normais foram calculados dividindo a soma das medidas tomadas das subamostras pelo número de plântulas mensuradas, e os resultados expressos em mm plântula ${ }^{-1}$. Para a aferição da massa seca foram utilizadas as mesmas plântulas, para tanto, as mesmas foram acondicionadas em sacos de papel e encaminhadas à estufa, com circulação de ar forçada e temperatura mantida a $70+$ $2^{\circ} \mathrm{C}$ até atingir massa constante. A massa seca das plântulas foi determinada em balança de precisão (NAKAGAWA, 1999), sendo os resultados expressos em mg plântulas ${ }^{-1}$.

A condutividade elétrica foi realizada conforme metodologia descrita por Krzyzanowski et al., (1991), sendo utilizadas três repetições de quatro subamostras cada, contendo 50 sementes, totalizando 600 sementes por tratamento. As sementes foram colocadas em béquer com 80 $\mathrm{mL}$ de água destilada e mantidas em germinador com temperatura constante de $15{ }^{\circ} \mathrm{C}, \quad 25^{\circ} \mathrm{C}$ e $35{ }^{\circ} \mathrm{C}$. A condutividade elétrica foi medida em $\mu \mathrm{S} / \mathrm{cm}^{-1}$ no condutivímetro de bancada Digimed CD-21, nos períodos de 3,6 e 24 horas e os resultados expressos em $\mathrm{mS} \mathrm{cm}^{-1} \mathrm{~g}^{-1} \mathrm{de}$ sementes.

A atividade respiratória foi determinada seguindo a metodologia modificada por Moraes et al., (2012), onde foram utilizadas três repetições com $4 \mathrm{~g}$ de sementes de pimenta. A medida da liberação de $\mathrm{CO}_{2}$ das sementes foi realizada em aparelho de Pettenkofer, constituído por dois frascos lavadores de gases contendo hidróxido de sódio $(\mathrm{NaOH})$, cuja finalidade foi reter o $\mathrm{CO}_{2}$ do ar do ambiente, um frasco para armazenamento das sementes isento de $\mathrm{CO}_{2}$ do ar ambiente e um frasco contendo hidróxido de bário $(\mathrm{BaOH})$, cuja função é reagir com o $\mathrm{CO}_{2}$ proveniente da atividade respiratória das sementes resultando na formação de carbonato de bário $\left(\mathrm{BaCO}_{3}\right)$, precipitado branco, formado na amostra na qual foi quantificado por titulação. Os frascos foram interligados por mangueira de silicone e esta acoplada a uma trompa aspiradora de ar. O fluxo de ar foi regulado por meio de uma torneira, de modo que permitiu regular a velocidade do ar por meio da contagem de bolhas formadas nos frascos. Após os referidos períodos de permanência no aparelho, foram coletadas três alíquotas de $\mathrm{BaCO}_{3}$, em cada repetição e adicionadas duas gotas de fenolftaleína, em seguida foram submetidas a titulação com ácido clorídrico (HCl) $0,1 \mathrm{~N}$. No ponto de viragem, foi registrado o volume de $\mathrm{HCl}$ gasto em cada uma das repetições, que foi diretamente relacionado com a quantidade de $\mathrm{CO}_{2}$ fixado pela solução de $\mathrm{BaOH}$, utilizado para a determinação da atividade respiratória das sementes, uma vez que o dióxido de carbono fixado é proveniente do seu processo de respiração.

$\mathrm{O}$ cálculo final da atividade respiratória foi realizado com base na média de quatro repetições, cujo resultado foi expresso em quantidade de $\mathrm{CO}_{2}$ liberado por grama de semente por hora ( $\mu \mathrm{g} \mathrm{CO}_{2}$ liberado $\mathrm{g}^{-1}$ semente $\mathrm{h}^{-1}$ ), utilizando-se a seguinte equação: N X D X 22, sendo, N= normalidade do ácido usado $(\mathrm{HCl} 0,1 \mathrm{~N}) ; \mathrm{D}=$ diferença entre a prova em branco e a amostra e $22=$ normalidade do $\mathrm{CO}_{2}$ para a atividade respiratória (AR) determinada no aparelho de Pettenkofer.

$\mathrm{O}$ experimento foi conduzido em delineamento experimental inteiramente casualizado, em esquema fatorial (1x3), constituído por uma espécie e três temperaturas $\left(15^{\circ} \mathrm{C}\right.$, $25{ }^{\circ} \mathrm{C}$ e $35{ }^{\circ} \mathrm{C}$ ), com três repetições. Os dados foram submetido a análise de variância e quando significativo, os dados relativos à variável curva de embebição foram submetidos análise de regressão polinomial de probabilidade, através do programa SigmaPlot 12.0. As demais variáveis foram comparadas pelo Teste de Tukey a $5 \%$ de probabilidade, com o auxílio do software SISVAR (FERREIRA, 2011).

\section{RESULTADOS E DISCUSSÃO}

O menor valor de porcentagem de plântulas germinadas na primeira contagem, realizada aos sete dias após a implantação do teste de germinação, foi observado nas sementes submetidas à temperatura de $15^{\circ} \mathrm{C}$ (Tabela 1). $\mathrm{O}$ teste de primeira contagem, frequentemente, tem sido utilizado para avaliar o vigor de sementes, principalmente por ser um método rápido, simples e que pode ser conduzido conjuntamente com o teste de germinação. Porém, nas condições avaliadas, o teste não detectou diferença significativa entre as temperaturas de $25^{\circ} \mathrm{C}$ e $35^{\circ} \mathrm{C}$, não se mostrando sensível na identificação de alteração no vigor das sementes de pimenta malagueta decorrente da exposição à temperatura mais elevada. Para minimizar a exposição das sementes a uma condição de ambiente que, muitas vezes, pode ser adversa, a germinação deve ser rápida e uniforme, possibilitando um eficiente estabelecimento de plântula.

A germinação de sementes é a retomada do crescimento do embrião, demonstrando sua aptidão em produzir uma planta normal, sob condições favoráveis de campo (BRASIL, 2009), e envolve uma sequência ordenada de eventos metabólicos que resulta na formação da plântula (DIAS et al., 2008). O processo germinativo é uma sequência de eventos fisiológicos influenciados por fatores intrínsecos e extrínsecos, que podem atuar sozinhos ou em interação com outros. Dentre os fatores que afetam diretamente a germinação das sementes, e são considerados essenciais, estão a temperatura e a luz (MARCOS FILHO, 2015).

Dentre estes fatores, a temperatura merece destaque, pois altera a velocidade de absorção de água e modifica a velocidade das reações bioquímicas que irão ocasionar o desdobramento e transporte das reservas e a síntese de substâncias no eixo embrionário (BEWLEY; BLACK, 1994), influenciando todas as reações bioquímicas e processos fisiológicos que determinam a germinação (POPINIGIS, 1985; CARVALHO; NAKAGAWA, 2012). Porém, não há um valor de temperatura ótimo e uniforme para todas as espécies (BEWLEY; BLACK, 1994), sendo que o processo germinativo ocorrerá dentro de determinados limites. Assim, 
pôde-se identificar três pontos críticos de temperatura para a germinação: mínimo, máximo e ótimo. A temperatura ótima ou ideal é aquela em que ocorre o máximo de germinação no menor espaço de tempo (CARVALHO; NAKAGAWA, 2012; MARCOS FILHO, 2015) e os limites máximos e mínimos são aqueles que, acima ou abaixo, o processo não se dá de forma eficiente.

A resposta das sementes em relação à temperatura é bastante variável, sendo que a maioria das espécies tropicais apresenta bom desempenho germinativo na faixa de 20 a 30 ${ }^{\circ} \mathrm{C}$ (BORGES; RENA, 1993), sendo esta faixa recomendada para a germinação de espécies do gênero Capsicum spp. (BRASIL, 2009). Sabe-se que, quanto maior a faixa de temperatura ótima para o desenvolvimento da espécie, mais amplo se torna o período recomendado para a semeadura e, também, maior a distribuição geográfica da espécie (BORGES; RENA, 1993).

A primeira contagem de germinação objetiva determinar o vigor relativo de sementes (KRZYZANOWSKI et al., 1999), através do registro de diferenças na velocidade de germinação, mesmo em lotes de sementes que apresentam porcentagens de germinação final semelhantes. Porém, os dados observados com esta pesquisa corroboram com Marcos Filho et al., (1987), que sugere que este teste não é muito sensível às pequenas diferenças de vigor.

Maiores valores de germinação foram observados em sementes de pimenta malagueta expostas à temperatura de 25 ${ }^{\circ} \mathrm{C}$ (Tabela 1). Embora a influência da temperatura no processo germinativo seja difícil de comparar, os efeitos benéficos na germinação a $25{ }^{\circ} \mathrm{C}$, verificados no presente estudo, corroboram com os dados encontrados por Yaklich e Orzolek (1977) e Van de Venter e Hoffman (1985), em sementes de outras espécies de pimenta. De forma geral, na faixa da temperatura ótima ocorre a maior porcentagem de germinação no menor intervalo de tempo, e nas temperaturas abaixo da faixa ótima ocorre redução da velocidade de germinação, entretanto, temperaturas supra ótimas promovem redução do potencial germinativo (MARCOS FILHO, 2015). A exposição à baixa temperatura $\left(15^{\circ} \mathrm{C}\right)$ afetou drasticamente a germinação de sementes de pimenta malagueta, inibindo o processo germinativo na espécie. Assim, a germinação praticamente nula, constatada na temperatura de $15^{\circ} \mathrm{C}$ está de acordo com observação de Okusanya (1978, 1980), quanto ao fato de que as sementes de muitas espécies tropicais são sensíveis à ocorrência de baixas temperaturas.

A influência da temperatura na germinação das sementes é essencial para entender os aspectos ecofisiológicos e bioquímicos desse processo (BEWLEY; BLACK, 1994), sendo importante a avaliação das mudanças ocasionadas nos parâmetros de porcentagem e velocidade de germinação. Neste contexto, a velocidade de germinação é um dos conceitos mais antigos relacionados ao vigor de sementes (AOSA, 1983). Desta forma, para o índice de velocidade de germinação (IVG), observa-se superioridade do tratamento de $25{ }^{\circ} \mathrm{C}$ em relação aos demais tratamentos (Tabela 1), evidenciando que o tempo necessário para alcançar a máxima expressão da germinação é altamente dependente desta variável, mesmo as sementes apresentando capacidade de germinação dentro de uma determinada amplitude de temperatura considerada como ótima para a espécie. De acordo com Carvalho e Nakagawa (2012), temperaturas inferiores ou superiores à ótima apresentam a tendência de reduzir a velocidade do processo germinativo, em função da exposição prolongada às condições adversas. Portanto, a temperatura influencia diretamente o processo germinativo, tanto no que diz respeito à germinação total como na velocidade da mesma.

Tabela 1. Primeira contagem, porcentagem e índice de velocidade de germinação (IVG) de sementes de pimenta malagueta (Capsicum frutescens L.), em temperaturas de 15 ${ }^{\circ} \mathrm{C}, 25^{\circ} \mathrm{C}$ e $35^{\circ} \mathrm{C}$.

\begin{tabular}{cccc}
\hline Temperatura & $\begin{array}{c}\text { Primeira Contagem } \\
(\%)\end{array}$ & $\begin{array}{c}\text { Germinação } \\
(\%)\end{array}$ & IVG \\
\hline $15^{\circ} \mathrm{C}$ & $0,16 \mathrm{~b}$ & $0,16 \mathrm{c}$ & $0,02 \mathrm{c}$ \\
$25^{\circ} \mathrm{C}$ & $64,50 \mathrm{a}$ & $84,34 \mathrm{a}$ & $7,36 \mathrm{a}$ \\
$35^{\circ} \mathrm{C}$ & $51,16 \mathrm{a}$ & $53,50 \mathrm{~b}$ & $5,18 \mathrm{~b}$ \\
\hline $\mathrm{CV}(\%)$ & 40,73 & 31,29 & 36,15 \\
\hline
\end{tabular}

*Médias seguidas por letras iguais não diferem entre si, pelo teste de Tukey, a $5 \%$ de probabilidade.

Em relação à análise de crescimento de plântulas normais, na temperatura de $15^{\circ} \mathrm{C}$ não houve a germinação das sementes o que, consequentemente, impossibilitou a avaliação deste tratamento. $\mathrm{Na}$ temperatura de $35^{\circ} \mathrm{C}$ observou-se, durante as contagens de sementes germinadas, que o crescimento da raiz primária e da parte aérea das plântulas não foi estimulado e, ao final do teste, estas se encontravam anormais e com sinais evidentes de deterioração, inclusive com grande proliferação de fungos, impossibilitando a avaliação do material proveniente deste tratamento. Desta forma, para o tratamento de $25{ }^{\circ} \mathrm{C}$, a análise de crescimento aponta para plântulas com o desenvolvimento normal de suas estruturas (Tabela 2), com raiz primária bem desenvolvida, alcançando comprimento de $3,71 \mathrm{~cm}$, e comprimento total de plântulas de $6,25 \mathrm{~cm}$. O tratamento ainda apresentou valores de massa de matéria fresca e seca de 0,19 e $0,02 \mathrm{mg}$ a cada 10 plântulas, respectivamente.

Tabela 2. Análise de crescimento de plântulas de pimenta malagueta (Capsicum frutescens L.), em condição de temperatura de $25^{\circ} \mathrm{C}$.

\begin{tabular}{ccccc}
\hline \multicolumn{2}{c}{ Comprimento $(\mathrm{cm})$} & \multicolumn{2}{c}{$\left.\begin{array}{c}\text { Massa de Matéria } \\
(\mathrm{mg} .10 \\
\text { plântulas }\end{array}{ }^{-1}\right)$} \\
\hline Parte aérea & Raiz & Total & Fresca & Seca \\
\hline 2,54 & 3,71 & 6,25 & 0,19 & 0,02 \\
\hline
\end{tabular}

A velocidade com que a água é absorvida durante o processo de germinação também pode variar em função da temperatura, sendo que em temperaturas mais altas, as sementes absorvem água mais rapidamente (CARVALHO; NAKAGAWA, 2012). Considerando que a embebição obedece a um padrão trifásico (BEWLEY; BLACK, 1994), a fase inicial do processo (fase I) constitui um fenômeno essencialmente físico, em função do potencial mátrico a semente absorve água por difusão, esta pode ser completada em até uma hora e meia, conforme foi observado no presente estudo (Figura 1). Desta forma, a fase inicial é dependente da absorção de água, enquanto a segunda depende da mobilização de reservas da semente (PRISCO et al., 1981). Assim, a segunda etapa (fase II) é caracterizada por uma série de eventos metabólicos preparatórios para a emissão da raiz primária, sendo que o tratamento de $35{ }^{\circ} \mathrm{C}$ apresentou superioridade aos demais, principalmente a partir dos 270 minutos. Este efeito é justificado pelo fato da temperatura estar altamente relacionada com o aumento do metabolismo 
inicial em sementes, consequentemente a temperatura de 15 ${ }^{\circ} \mathrm{C}$ foi a que apresentou os menores valores para esta fase, no mesmo período avaliado.

A fase III é representada pelo início visível da germinação (CARVALHO; NAKAGAWA, 2012), através do rompimento do tegumento e protrusão radicular, portanto, é altamente relacionada à viabilidade efetiva da semente, sendo o tratamento de $25^{\circ} \mathrm{C}$ mais eficiente em estimular o crescimento do embrião. Nota-se que os tratamentos de $15^{\circ} \mathrm{C}$ e $35^{\circ} \mathrm{C}$ também foram capazes de alcançar esta fase da curva de embebição, porém não apresentaram eficiência em originar plântulas normais. Em função do período de exposição destas sementes à condição de temperatura baixa, neste caso, caracterizada por $15{ }^{\circ} \mathrm{C}$, o processo germinativo foi interrompido nesta fase, com a consequente morte dos tecidos radiculares.

Figura 1. Curva de embebição de sementes de pimenta malagueta (Capsicum frutescens L.), em temperaturas de 15 ${ }^{\circ} \mathrm{C}, 25^{\circ} \mathrm{C}$ e $35^{\circ} \mathrm{C}$.

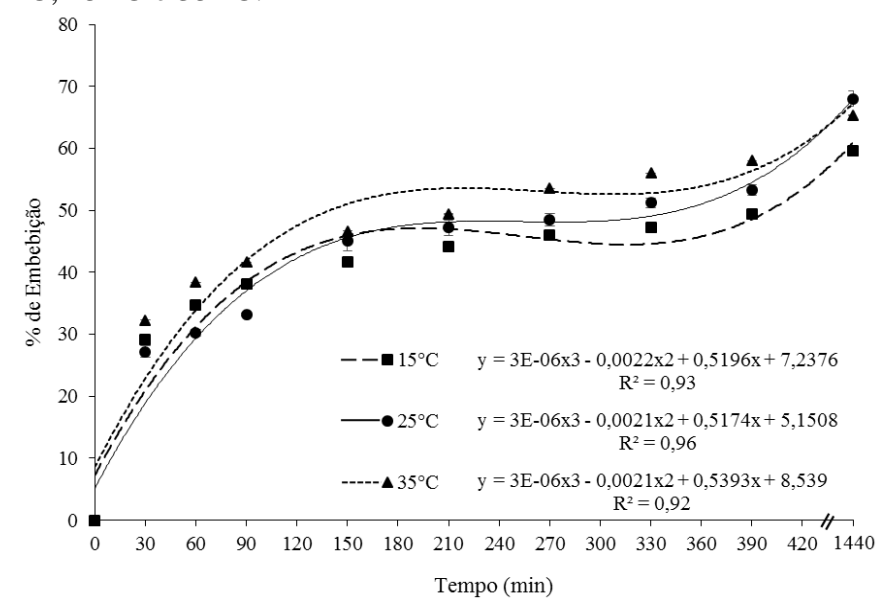

Assim, a embebição, principalmente durante a fase I, é acompanhada pela liberação de açúcares, aminoácidos e eletrólitos em quantidades variáveis com o estado de organização do sistema de membranas. Vários autores destacaram que a taxa de liberação de eletrólitos é muito elevada no início do processo de embebição; contudo, com o decorrer do tempo esta situação se altera, à medida que ocorre a reorganização das membranas celulares (SIMON; RAJAHARUN, 1972; BECWAR et al., 1982; BEWLEY; BLACK, 1994). Neste sentido, o teste de condutividade elétrica é uma avaliação indireta do estado de organização das membranas celulares, baseado na determinação da quantidade de lixiviados liberados pelas sementes na solução de embebição (VIEIRA; KRZYZANOWSKY, 1999). Portanto, o valor da condutividade elétrica medida na solução de embebição de sementes é função da quantidade de íons lixiviados, estando diretamente relacionado com a integridade das membranas celulares. Em relação a este teste (Tabela 3), pôde-se verificar que os valores lixiviados pelas sementes aumentaram durante o período de embebição, constatação feita também por outros autores (TORRES; PEREIRA, 2010; VIEIRA; DUTRA, 2006; VIDIGAL et al., 2008).

De acordo com Leopold (1980), o efeito da temperatura é verificado na velocidade de embebição e na lixiviação de eletrólitos do interior das células para o meio externo. Temperaturas mais elevadas influenciam a dissociação de íons e, com isso, reduzem a viscosidade da solução, resultando em valores mais elevados de condutividade. Contudo, a liberação foi maior quando as sementes foram submetidas à temperatura de $35^{\circ} \mathrm{C}$, evidenciando o efeito deste tratamento no aumento do grau de deterioração das membranas e, consequentemente, no maior conteúdo de exsudatos lixiviados pelas sementes. Pode-se inferir que o teste de condutividade elétrica conduzido à temperatura de 25 ${ }^{\circ} \mathrm{C}$ apresentou os melhores resultados para sementes de pimenta malagueta, em relação às temperaturas de 15 e $35^{\circ} \mathrm{C}$ (Tabela 3).

Tabela 3. Condutividade elétrica de sementes de pimenta malagueta (Capsicum frutescens L.), em temperaturas de 15 ${ }^{\circ} \mathrm{C}, 25^{\circ} \mathrm{C}$ e $35^{\circ} \mathrm{C}$.

\begin{tabular}{cccc}
\hline \multicolumn{4}{c}{ Condutividade Elétrica $\left(\mu \mathrm{S} \mathrm{cm}^{-1} \mathrm{~g}^{-1}\right.$ semente) } \\
\hline \multirow{2}{*}{ Temperatura } & \multicolumn{3}{c}{ Período (horas) } \\
\cline { 2 - 4 } & 3 & 6 & 24 \\
\hline $15^{\circ} \mathrm{C}$ & $42,62 \mathrm{~b}$ & $44,04 \mathrm{~b}$ & $47,17 \mathrm{~b}$ \\
$25^{\circ} \mathrm{C}$ & $24,89 \mathrm{c}$ & $27,62 \mathrm{c}$ & $28,39 \mathrm{c}$ \\
$35^{\circ} \mathrm{C}$ & $67,22 \mathrm{a}$ & $73,12 \mathrm{a}$ & $79,63 \mathrm{a}$ \\
$\mathrm{CV}(\%)$ & 6,53 & 7,19 & 7,68 \\
\hline
\end{tabular}

* Médias seguidas de letras diferentes na linha não diferem entre si, pelo teste de Tukey a $5 \%$ de probabilidade.

Desta forma, pode-se observar ainda que os valores de condutividade mantiveram a mesma tendência durante os períodos avaliados (3, 6 e 24 horas), sendo que o tratamento de $35{ }^{\circ} \mathrm{C}$ apresentou desempenho inferior, com maior presença de exsudatos, possibilitando a ordenação dos tratamentos de temperatura ainda nas horas iniciais. Este aspecto é importante, pois permite a realização do teste em menor período de tempo, possibilitando a obtenção rápida e eficaz dos resultados. De acordo com Oliveira e Novembre (2005), avaliando o vigor de diferentes lotes de sementes de pimentão, é possível a identificação de lotes com vigor mais elevado em apenas uma hora de imersão de sementes.

Membranas mal estruturadas e células danificadas estão, geralmente, associadas com o processo de deterioração da semente e, portanto, com sementes de baixo vigor (AOSA, 1983). Assim, sementes com menor potencial fisiológico, em decorrência do processo deteriorativo, apresentamtêm a capacidade de reorganização de membranas reduzida, havendo maior perda de solutos para o meio, determinando decréscimo nas reservas da semente e prejuízo na uniformidade e rapidez do processo germinativo (AOSA, 1983; BEWLEY; BLACK, 1994; HAMPTON; TEKRONY, 1995; VIEIRA; KRZYZANOWSKI, 1999).

A respiração é a primeira atividade metabólica que acompanha a reidratação da semente, que de valores ínfimos, sobe a níveis bastante elevados poucas horas após o início da embebição, ocorrendo incremento no metabolismo e ativação de enzimas respiratórias e hidrolíticas (HOFS et al., 2004; MARENCO; LOPES, 2005), sendo a principal produtora de energia para a continuidade do metabolismo. Em relação à atividade respiratória, em sementes secas, observou-se que a temperatura de $15^{\circ} \mathrm{C}$ (Figura 2) apresentou superioridade em relação aos demais tratamentos, provavelmente pelo fato de que com o aumento da respiração, ocorre acréscimo de calor na semente, o que poderia ser uma forma de adaptação à temperatura baixa. Porém, em sementes secas, a separação dos tratamentos não foi tão eficiente. Já nas sementes úmidas, verificou-se maior atividade respiratória no tratamento de 25 ${ }^{\circ} \mathrm{C}$, evidenciando a superioridade deste tratamento em relação 
aos demais, uma vez que sementes mais vigorosas tendem a apresentar maior atividade respiratória do que sementes com menor vigor, em um mesmo período de tempo. Assim, podese inferir que o tratamento de $25^{\circ} \mathrm{C}$ não influenciou negativamente a qualidade fisiológica das sementes, podendo ser comprovado através dos demais testes de vigor avaliados. Assim, de acordo com Castro (2011) e Dutra (2011), taxas elevadas de respiração podem ser explicadas pela rápida retomada da atividade das sementes.

Figura 2. Atividade respiratória de sementes secas (A) e úmidas (B) de pimenta malagueta (Capsicum frutescens L.), em temperaturas de $15^{\circ} \mathrm{C}, 25^{\circ} \mathrm{C}$ e $35^{\circ} \mathrm{C}$.

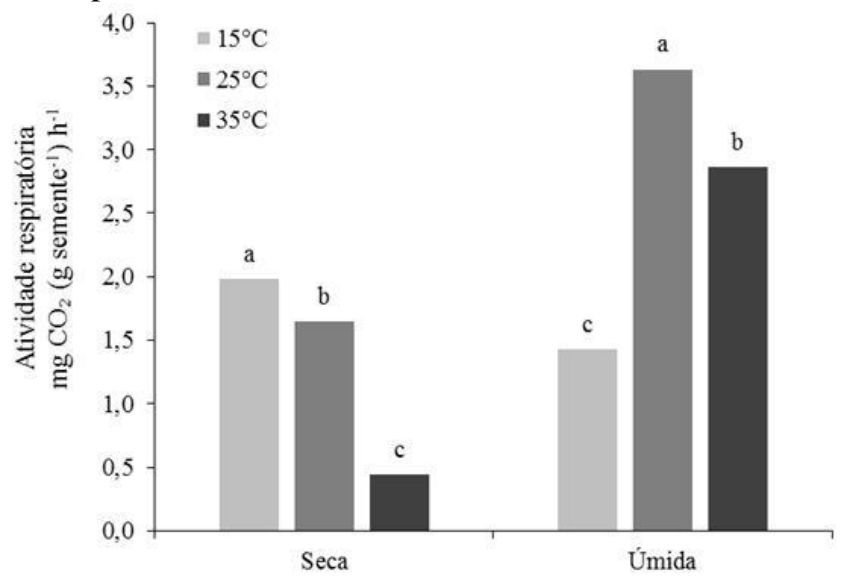

Nas sementes em processo de deterioração, uma das principais alterações no vigor está relacionada à redução da atividade respiratória (FERGUSON et al., 1990), como foi observado com a realização deste estudo, o que foi evidenciado na temperatura de $15{ }^{\circ} \mathrm{C}$, em sementes úmidas. Os resultados estão de acordo com o observado por Pereira (2012), onde afirma que as alterações responsáveis pela queda de vigor ocorrem paralelamente à redução da taxa respiratória das sementes.

A atividade e integridade das mitocôndrias de embriões viáveis aumentam a partir do início da embebição, o que torna mais eficiente a produção de ATP, refletindo a elevação do consumo de oxigênio e consequente elevação na produção de gás carbônico (BEWLEY; BLACK, 1994). Pode-se inferir, ainda, que a metodologia utilizada para a quantificação da atividade respiratória foi suficiente para permitir a separação dos tratamentos, quando utilizada com os demais testes de referência utilizados neste trabalho.

A avaliação da atividade respiratória em laboratório, utilizando o método Pettenkofer, foi considerada por Mendes et al., (2009) uma alternativa aos testes tradicionais para a determinação do vigor de um lote de sementes. O uso desse método mostrou-se eficiente para avaliar o vigor de sementes de pimenta e pimentão (PEREIRA, 2012), porém, pesquisas adicionais utilizando esse método para avaliar lotes de sementes de hortaliças ainda são necessárias.

\section{CONCLUSÕES}

A melhor temperatura para a germinação de sementes de pimenta malagueta foi de $25^{\circ} \mathrm{C}$, com concordância de todos os testes realizados.
Os testes rápidos de vigor, como condutividade elétrica e atividade respiratória foram eficientes para avaliar o efeito das temperaturas adversas sob as sementes.

A espécie em estudo não tolera semeaduras em condições de temperatura de $15^{\circ} \mathrm{C}$ e $35^{\circ} \mathrm{C}$.

Devido ao fato das temperaturas avaliadas serem próximas as faixas indicadas para a cultura são necessários maiores estudos, para verificar a ocorrência de germinação satisfatória nas temperaturas entre 20 e $30{ }^{\circ} \mathrm{C}$.

\section{REFERÊNCIAS}

AOSA, ASSOCIATION OF OFFICIAL SEED ANALYSTS. Seed vigor test committee: seed vigor testing handbook. Lincoln, 1983. 88 p. (Contribuition, 32).

BATISTA, T. B.; BINOTTI, F. F. S.; CARDOSO, E. D.; BARDIVIESSO, E. M.; COSTA, E. Aspectos fisiológicos e qualidade de mudas da pimenteira em resposta ao vigor e condicionamento das sementes. Bragantia, v.74. 2015.

BECWAR, M. R.; STANWOOD, P. C.; ROSS, E. E. Dehydration effects imbibitional leakage from dessiccation sensitive seeds. Plant Physiology, v.69, n.4, p.1132-1135, 1982.

BERGO, C. L.; SILVA, R. C.; OHLSON, O. C.; BIASI, L. A.; PANOBIANCO, M. Luz e temperatura na germinação de sementes de pimenta longa (Piper hispidinervum) e pimentade-macaco (Piper aduncum). Revista Brasileira de Sementes. v.32, n. 3, p.170-176, 2010.

BEWLEY, J. D.; BLACK, M. Seeds: physiology of development and germination. 2nd ed. New York: Plenum, 1994. 445p.

BORGES, E. E. de; RENA, A. B. Germinação de sementes. In: AGUIAR, I.B.; PINARODRIGUES, F.C.M.; FIGLIOLIA, M.B. (Ed.). Sementes florestais tropicais. Brasília: ABRATES, 1993. p.83-127.

BRASIL. Ministério da Agricultura, Pecuária e Abastecimento. Regras para análise de sementes. Ministério da Agricultura Pecuária e Abastecimento. Secretaria de Defesa Agropecuária. Brasília, DF: Mapa/ACS, 2009. 187p.

CAIXETA, F.; VON PINHO, E. V. R.; GUIMARÃES, R. M.; PEREIRA, P. H. A. R.; CATÃO, H. C. R. M.; CLEMENTE, A. C. S. Determinação do ponto de colheita na produção de sementes de pimenta malagueta e alterações bioquímicas durante o armazenamento e a germinação. Científica, v.42, n.2, p.187-197, 2014.

CARVALHO, N. M.; NAKAGAWA, J. Sementes: ciências, tecnologia e produção. 2.ed. Campinas: Fundação Cargill, 2000. 565p.

CASTRO, M. B. Avaliação da qualidade fisiológica de sementes de milho por meio da atividade respiratória. 2011. 67p. Dissertação (Mestrado em Fitotecnia) - Universidade Federal de Lavras, Lavras, 2011. 
CATELAM, K. T. Estudo da cinética de secagem de pimenta malagueta (Capsicum frutescens) e influência da temperatura no teor de capsaicina. Tese em Engenharia e Ciência de Alimentos Universidade Estadual Paulista "Júlio de Mesquita Filho”, São José do Rio Preto, 2016.

DIAS, M. A; LOPES, J. C.; CORRÊA, N. B.; DIAS, D. C. F. Germinação de sementes e desenvolvimento de plantas de pimenta malagueta em função do substrato e da lâmina de água. Revista Brasileira de Sementes, v.30, n.3, p.115-121, 2008.

DOMENICO, C. I.; COUTINHO, J. P.; GODOY, H. T.; MELO, A. MT. Caracterização agronômica e pungência em pimenta de cheiro. Horticultura Brasileira, v.30, p.466-472, 2012.

DUTRA, S. M. F. Qualidade fisiológica de sementes de pimenta Habanero (Capsicum chinenses Jacquin). 2011. 47p. Monografia (Graduação em Agronomia) - Universidade Federal de Lavras, Lavras, 2011.

EREMRENA, P. O.; MENSAH, S. I. Effect of plant growth regulators and nitrogenous compounds on seed germination of pepper (Capsicum frutescens $\mathrm{L}$ ). Journal of Applied Sciences and Environmental Management, v. 20 , n.2, p.242-250, 2016.

FERGUSON, J. M.; TEKRONY, D. M.; EGLI, D. M. Changes during early soybean seed and axes deterioration: II. Lipids. Crop Science, v.30, n.1, p.179-182, 1990.

FERREIRA, D. F. Sisvar: a computer statistical analysis system. Ci Agrotecnol, v.35, p.1039-42, 2011.

GORDIN, C. R. B.; MARQUES, R. F.; MASETTO, T. E.; SCALON, S. P. Q. Germinação, biometria de sementes e morfologia de plântulas de Guizotia abyssinica Cass. Revista Brasileira de Sementes, v.34, n.4, p.619-627, 2012.

VAN DE VENTER, H. A.; HOFFMAN, R. Osmoconditioning of seeds of sweet pepper (Capsicum annuum L.). South African Journal of Plant and Soil, n.2, v.3, p.161-163,1985.

HAMPTON, J. G.; TEKRONY, D. M. (Ed.). Handbook of vigour test methods. 3 ed. Zurich: The International Seed Testing Association, 1995. 117p.

HOFS, A.; SCHUCH, L. O.; PESKE, S. T.; BARROS, A. C. S. A. Efeito da qualidade fisiológica das sementes e da densidade de semeadura sobre o rendimento de grãos e qualidade industrial em arroz. Revista Brasileira de Sementes, v. 26, n.1, p.55-62, 2004.

KRZYZANOWSKI, F. C.; FRANÇA-NETO, J. B.; HENNING, A. A. Relato dos testes de vigor disponíveis para grandes culturas. Informativo ABRATES, Londrina, v.1, n.2, p.15-50, 1991.

KRZYZANOWSKI, F. C.; VIEIRA, R. D.; FRANCA NETO, J. de B. (Ed.). Vigor de sementes: Conceitos e testes. Londrina: ABRATES, 1999. 218p.
LEOPOLD, A. C. Temperature effects on soybean inibition and leakage. Plant Physiology, Lancaster, v.65, p.1096-1098, 1980.

MAGUIRE, J. D. Speed of germination and in selection and evaluation for seedlings emergence and vigor. Crop Science, Madison, v.2, n.2, p.176-177, 1962.

MARCOS FILHO, J. Fisiologia de sementes de plantas cultivadas. Piracicaba: FEALQ, 2005. 495p.

MARCOS FILHO, J.; CÍCERO, S. M.; SILVA, W. R. Avaliação da qualidade das sementes. Piracicaba: FEALQ, 1987. 230p.

MARENCO, R. A.; LOPES, N. F. Fisiologia Vegetal: Fotossíntese, Respiração, Relações Hídricas e Nutrição Mineral. Universidade Federal de Viçosa, Brasil. 2005. 451p

MENDES, C. R.; MORAES, D. M., LIMA, M. G. S.; LOPES, N. F. Respiratory activity for the differentiation of vigor on soybean seeds lots. Revista Brasileira de Sementes, v.31, p.171-176. 2009.

MORAES, D. M.; BANDEIRA, J. M.; MARINI, P.; LIMA, M.G. de S.; MENDES, C.R. Práticas Laboratoriais em fisiologia vegetal. Editora Cópias Santa Cruz Ltda., Pelotas, 2012. 162p.

NAKAGAWA, J. Testes de vigor baseados no desempenho das plântulas. In: KRZYZANOSKI, F. C.; VIEIRA, R. D.; FRANÇA NETO, J. B. (Ed.). Vigor de sementes: conceitos e testes. Londrina: ABRATES, 1999. p.2.1-2.24.

NASCIMENTO, W. M. Condicionamento osmótico de sementes de hortaliças visando a germinação em condições de temperaturas baixas. Horticultura brasileira, Brasília, v.23, n.2, p.211-214, 2005.

OKUSANYA, O. T. The effects of light and temperature on germination and growth of Luffa aegyptiaca. Physiologia Plantarum, v.44, p.429-433, 1978.

OKUSANYA, O. T. Germination and growth of Celosia cristata L., under various light and temperature regimes. American Journal of Botany, v.67, p.854-858, 1980.

OLIVEIRA, A. K. M; BARBOSA, L. A. Efeitos da temperatura na germinação de sementes e na formação de plântulas de Cedrela fissilis. Floresta, Curitiba/PR. 2014. v. 44.

OLIVEIRA, S. R. S.; NOVEMBRE, A. D. L. C. Teste de condutividade elétrica para as sementes de pimentão. Revista Brasileira de Sementes, Londrina, v.27, n.1, p.31-36, 2005.

PAULUS, D.; VALMORBIDA, R.; SANTIN, A.; TOFFOLI, E.; PAULUS, E. Crescimento, produção e qualidade de frutos de pimenta (Capsicumannuum) em diferentes espaçamentos. Horticultura brasileira. v.33, n.1, p.91-100, 2015. 
PEREIRA, E. M. Avaliação da qualidade fisiológica de sementes de pimenta e pimentão por meio da atividade respiratória. Dissertação (mestrado) - Universidade Federal de Lavras: UFLA, 69 p. 2012.

POPINIGIS, F. Fisiologia da semente. Brasília: AGIPLAN, 1985. 289p.

PRISCO, J. T.; ENÉAS FILHO, J. R.; GOMES FILHO, E. Effect of $\mathrm{NaCl}$ on cotyledon starch mobilization during germination of Vigna unguiculata (L.) Walp seed. Revista Brasileira de Botânica, v.11, n.1, p.63-71, 1981.

RICCI, N; PACHECO, A. C.; CONDE, A. S.; CUSTÓD, C. C. Qualidade de sementes de pimenta jalapenho em função da maturação e tempo de permanência nos frutos. Pesquisa Agropecuária Tropical, v. 4, n. 2, p. 123-129, 2013.

SIMON, E. W.; RAJA-HARUN, R. M. Leakage during seed imbibition. Journal of Experimental Botany, London, v.23, p.1076-1085, 1972.

TORRES, S. B.; PEREIRA, R. A. Condutividade elétrica em sementes de rúcula. Revista Brasileira de Sementes, v.32, n.4, p. 58-70, 2010.

VIDIGAL, D. S.; LIMA, J. S.; BHERING, M. C.; DIAS, D. C. F. S. Teste de condutividade elétrica para sementes de pimenta. Revista Brasileira de Sementes, v.30, n.1, p.168174, 2008.

VIEIRA, R. D.; KRZYZANOWSKI, F. C. Teste de condutividade elétrica. In: KRZYZANOWSKY, F. C.; VIEIRA, R. D.; FRANÇA-NETO, J. B. (Ed.). Vigor de sementes: conceitos e testes. Londrina: ABRATES, 1999. p.4-1-4-26.

VIEIRA, R. D; DUTRA, A. S. Condutividade elétrica em sementes de Abóbora, híbrido Bárbara. Horticultura Brasileira, v.24, n.3, p.305-308, 2006.

YAKLICH, R. W.; ORZOLEK, M. D. Effect of polyethylene glycol- 6000 on pepper seed. Horticultural Science, v.12, p.263-264, 1977. 